\title{
Clinical significance and risk factors of urethrovesical anastomotic urinary leakage following robot-assisted radical prostatectomy: a multi-institutional study
}

Shigenori Kakutani ${ }^{1,2 \dagger}$, Yuta Takeshima ${ }^{3 \dagger}$, Yuta Yamada ${ }^{2 *}$, Tetsuya Fujimura ${ }^{4}$, Shoichi Nagamoto ${ }^{5}$, Yutaka Enomoto ${ }^{5}$, Yuji Hakozaki ${ }^{2}$, Naoki Kimura ${ }^{2}$, Taro Teshima ${ }^{2}$, Yoshiyuki Akiyama ${ }^{2}$, Yusuke Sato ${ }^{2}$, Taketo Kawai ${ }^{2}$, Daisuke Yamada² and Haruki Kume ${ }^{2}$

\begin{abstract}
Background: There has been a limited number of reports on the significance and risk factors of urethrovesical anastomotic urinary leakage (AUL) following robot-assisted radical prostatectomy (RARP). We aimed to analyze the clinical significance of AUL and evaluated its risk factors.

Methods: We conducted a multi-institutional study to review patients with prostate cancer undergoing RARP in three centers (The University of Tokyo Hospital, Mitsui Memorial Hospital, and Chiba Tokushukai Hospital). "Positive AUL" was defined as urinary extravasation at the anastomosis detected by post-operative cystogram and was further categorized into minor or major AUL. Univariate and multivariate analyses were performed to identify predictors of AUL. Postoperative continence rates and time to achieve continence were also analyzed.
\end{abstract}

Results: A total of 942 patients underwent RARP for prostate cancer in 3 centers. Of these patients, a cystogram after the RARP procedure was not performed in 26 patients leaving 916 patients for the final analysis. AUL was observed in 56 patients (6.1\%); 34 patients (3.7\%) with minor AUL and 22 patients (2.4\%) with major AUL. Patients with major AUL exhibited a significantly longer time to achieve continence than those without major AUL. Multivariate analysis demonstrated that longer console time ( $\geq 184 \mathrm{~min}$ ) was significantly associated with overall AUL, and higher body mass index $\left(\geq 25 \mathrm{~g} / \mathrm{kg}^{2}\right)$ was a significant predictor of both major and overall AUL.

Conclusions: The presence of major AUL was associated with the achievement of urinary continence, suggesting clinical relevance of its diagnosis by postoperative cystogram. A selective cystogram has been proposed for high-risk cases. Furthermore, identification of the risk factors of AUL will lead to optimal application.

Keywords: Anastomotic urinary leakage, Urethrovesical anastomosis, Urinary incontinence, Robot-assisted radical prostatectomy, RARP

*Correspondence: yyamada2029@gmail.com

†Shigenori Kakutani and Yuta Takeshima have contributed equally to this work

${ }^{2}$ Department of Urology, Graduate School of Medicine, The University of Tokyo, 7-3-1 Hongo, Bunkyo-Ku, Tokyo 113-8655, Japan

Full list of author information is available at the end of the article

\section{Background}

Robot-assisted radical prostatectomy (RARP) has become the most utilized treatment modality for localized prostate cancer in the past two decades [1,2]. The improved vision of pelvic anatomy and the dexterity of robotassisted surgical arms provided by RARP have allowed 
more precise and watertight urethrovesical anastomosis (UVA). A correlation between surgeon experience and quality of anastomosis has been reported, suggesting its utility as a benchmark of surgical skill for RARP [3]. This, in turn, has naturally led many to suggest that the improved quality of anastomosis resulted in reducing the incidence of urethrovesical anastomotic urinary leakage (AUL) following RARP as an advantage over conventional open retropubic radical prostatectomy (RRP) $[4,5]$. However, there is presently little evidence to corroborate this, perhaps owing to a low number of events as in one study detecting no difference in AUL incidence between RRP and RARP (2.9\% vs. $3.2 \%, P$ value $=0.49)$ [6]. In fact, we found that there is a lack of consensus on the importance of AUL in general, concerning its effect on the postoperative outcome, and its risk factors. A major factor contributing to this is that postoperative cystograms to detect AUL are not routinely taken at many centers around the world, leading to a significant variation in the definition of AUL, with some groups using findings of postoperative cystogram and others using confirmation of urine in the drain [7]. In 2008, Williams et al. proposed a systematic definition of AUL detected by cystogram and clarified its classification depending on severity and necessity of intervention, for objective quantification of AUL in future studies [8]. In this study, we conducted a routine postoperative cystogram following RARP and utilized this classification of cystographic findings to examine AUL objectively. Recognizing the factors associated with AUL is clinically important, since it may avert routine cystogram and provide beneficial information to surgeons for determination on patient selection regarding post-operative cystogram. To our knowledge, there is only one study that had presented statistically significant factors of AUL by performing a multivariate analysis in patients undergoing RARP [9]. Moreover, this is the first multi-institutional study to investigate the effect of AUL after RARP and its risk factors.

\section{Methods}

\section{Patient population}

The study was approved by the ethical committee of The University of Tokyo Hospital (ID: 2020039NI), the ethical committee of Mitsui Memorial hospital (ID: 2020C30), and the committee of Chiba Tokushukai Hospital (ID: 184). All clinical data were prospectively collected in a customized database and retrospectively analyzed. RARP was performed by multiple surgeons using da $\mathrm{Vinci}^{\circledR} \mathrm{Si}$ or Xi Surgical Systems (Intuitive Surgical, Sunnydale, CA, USA) by a transperitoneal approach in 671 patients from Nov 2011 to May 2019 at The University of Tokyo Hospital, in 164 patients on the Si System from May 2017 to May 2019 at Chiba Tokushukai Hospital, and in 107 patients on the Xi System from Nov 2017 to May 2019 at Mitsui Memorial Hospital. Patients with non-metastatic prostate cancer with or without neoadjuvant hormonal therapy were treated with RARP. Contraindication of RARP included a history of rectal surgery or the presence of severe comorbidities.

\section{Surgical technique}

RARP was performed and carried out in the same fashion in all 3 centers as previously described; UVA was completed after Rocco's posterior rhabdosphincter reconstruction by a continuous running closure using two $3 / 0$ absorbable monofilaments tied end-to-end $[10,11]$. The integrity of UVA was routinely checked by an intraoperative flush test using $50-150 \mathrm{~mL}$ saline through the catheter. An additional suture was performed when needed to attain watertight anastomosis. A Foley catheter was placed into the bladder and the balloon was filled with $10 \mathrm{~mL}$ of water.

\section{Post-surgical examination}

At 6-8 days after RARP, a cystogram of anteroposterior and oblique view was taken before removal of the urethral catheter by instilling $40-120 \mathrm{~mL}$ of saline-diluted iodinated contrast medium into the bladder. Positive AUL was defined as the 'presence of urinary extravasation determined by cystogram'. In the absence of AUL, we removed the urethral catheter immediately or the next morning. Positive AUL was reviewed and subclassified into two categories; minor AUL within $6 \mathrm{~cm}$ of the UVA, in accordance with 'grade 1 urethrovesical leak', and major AUL beyond $6 \mathrm{~cm}$ from the UVA, in accordance with 'grades 2 and 3 urethrovesical leaks' [8]. In patients with minor AUL, the catheter was removed within a day after the cystogram. In patients with major AUL, the catheter was placed in situ until leakage was either undetectable on a repeat cystogram or recovered to minor AUL. Time to recovery of the urinary continence was calculated from the removal of the urethral catheter.

\section{Statistical evaluation}

The collected clinical data were analyzed by using JMP Pro 15.1 software (SAS Institute, Cary, NC, USA). Valuables such as age, body mass index (BMI), initial PSA value, prostate volume, console time, blood loss volume, surgeon experience $(\geq 20,40$, or 100 cases), cavernous nerve preservation status, and pathological findings (pGS $\geq 8, \mathrm{pT} 3 \geq$, positive surgical margin) were collected. Univariate and multivariate analyses using logistic regression analysis were performed to identify factors predicting AUL. Parameters that were significantly associated with AUL in the univariate analysis and known factors based on the previous reports were included in 
the multivariate analyses [12]. Kaplan-Meier curves were drawn, and the Wilcoxon test was used to analyze the time to recovery of continence ( $\leq$ one pad per day) after successful removal of the catheter. Cut-off values were basically determined by the median values of each parameter, except for BMI and prostate weight which were rounded to a clinically useful number. All tests were two-sided and a $P$ value of $<0.05$ was regarded as statistically significant.

\section{Results}

Patient characteristics and perioperative status are shown in Table 1. A total of 942 patients underwent RARP procedure for prostate cancer in 3 centers (The University of Tokyo Hospital, Chiba Tokushukai Hospital, and Mitsui Memorial Hospital). The records of cystogram after RARP procedure was not available in 26 patients. A total of 916 patients were investigated for the final analysis. The number of patients included in this study was 645 patients for The University of Tokyo Hospital, 164 for Chiba Tokushukai Hospital, and 107 for Mitsui Memorial Hospital. 860 patients (93.9\%) and 56 patients (6.1\%) had negative and positive AUL, respectively. Of the patients with positive AUL, 34 (60.7\%) were classified as minor AUL and 22 (39.3\%) as major AUL. The median duration of catheterization was 7 days (IQR 6-8).

Time to recovery of continence ( $\leq 1 \mathrm{pad} /$ day) was significantly longer in patients with major AUL than those without major AUL (Fig. 1).

In the univariate analysis, BMI $\left(\geq 25 \mathrm{~kg} / \mathrm{m}^{2}\right)$ and console time $(\geq 184 \mathrm{~min})$ were significantly associated with overall AUL (Table 2; $P=0.03$ and $P=0.04$,

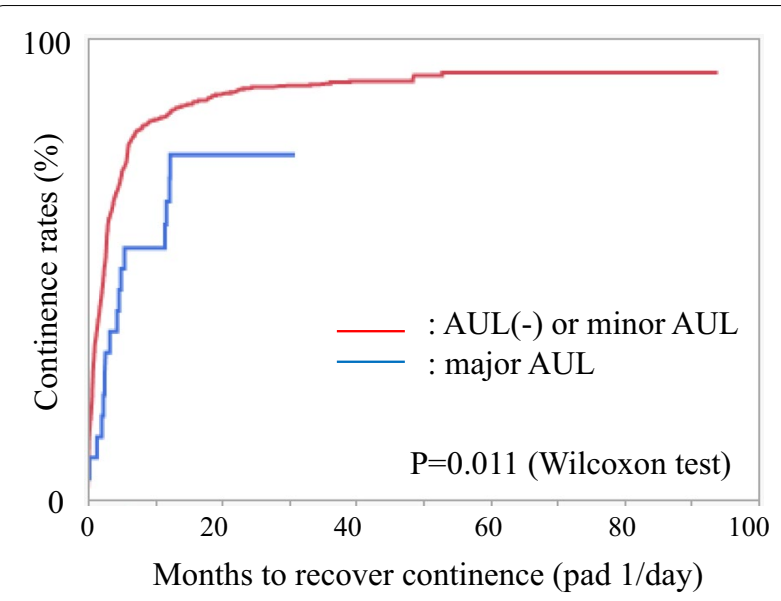

Fig. 1 Months to recover continence in patients with or without major anastomotic urinary leakage. Kaplan-Meier method analysis revealed that there was a significant delay in days to recover continence less than one pad per day in patients with major AUL

respectively). In the multivariate analysis, console time remained as the significant predictor of overall AUL. A similar analysis was conducted for major AUL (Table 3). In the univariate analysis, BMI $\left(\geq 25 \mathrm{~kg} / \mathrm{m}^{2}\right)$ and console time ( $\geq 184 \mathrm{~min}$.) were associated with major AUL (Table 3; $P<0.01$ and $P=0.04$, respectively). There was a tendency of observing more major and overall AUL in patients with prostate weight $>40 \mathrm{~g}$ (Tables 2, 3; $P=0.08, P=0.006$, respectively). In the multivariate analysis, BMI remained a significant predictor of major AUL. There was no significant association between surgeon experience and overall/major AUL.

Table 1 Patients demographics

\begin{tabular}{|c|c|c|c|c|c|}
\hline & \multicolumn{3}{|l|}{ Leakage (+) } & \multirow[t]{2}{*}{ Leakage (-) } & \multirow[t]{2}{*}{ Total } \\
\hline & Minor & Major & Minor + major & & \\
\hline \multicolumn{6}{|c|}{ Anastomotic urinary leakage after RARP } \\
\hline Number of patients (\%) & $34(3.7)$ & $22(2.4)$ & $56(6.1)$ & $860(93.9)$ & 916 \\
\hline Age, (years) & $68.5(64-72)$ & $65(58-70)$ & $68(63-72)$ & $68(64-73)$ & $68(64-73)$ \\
\hline $\mathrm{BMI}\left(\mathrm{kg} / \mathrm{m}^{2}\right)$ & $24.1(22.2-26.5)$ & $25.6(24.4-28.1)$ & $24.9(22.9-26.7)$ & $23.8(21.9-25.6)$ & $23.9(22-25.6)$ \\
\hline PSA (ng/mL) & $8.8(6.2-12.6)$ & $8.3(5.9-15.3)$ & $8.5(6.2-12.9)$ & $7.6(5.5-11.0)$ & $7.6(5.6-11.1)$ \\
\hline Operation duration (min) & $279(203-341)$ & $295(232-379)$ & $289(215-349)$ & $240(195-283)$ & $241(196-287)$ \\
\hline Console duration (min) & $212.5(155-266)$ & $233(168-322)$ & $221.5(164-271)$ & $183(143-221)$ & $184(145-226)$ \\
\hline Prostate weight (g) & $43.1(34-70)$ & $50.5(40-74)$ & $46.5(38-72)$ & $40.5(32-52)$ & $41(32-53)$ \\
\hline Blood loss volume $(\mathrm{mL})$ & $300(100-725)$ & $352(174-666)$ & $326(150-700)$ & $221(100-442)$ & $230(100-450)$ \\
\hline $\mathrm{pGS} \geq 8(\%)$ & 29.4 & 22.7 & 26.8 & 28.2 & 29.8 \\
\hline pT stage $\geq 3(\%)$ & 23.5 & 40.9 & 30.4 & 30.6 & 30.6 \\
\hline PSM (\%) & 17.6 & 18.2 & 17.9 & 21.3 & 21.7 \\
\hline
\end{tabular}

Median values are shown (interquartile range)

RARP, robot-assisted radical prostatectomy; BMI, body mass index; PSA, prostate specific antigen; pGS, pathological Gleason score; PSM, positive surgical margin 
Table 2 Univariate and multivariate analysis to predict overall anastomotic urinary leakage (AUL)

\begin{tabular}{|c|c|c|c|c|c|}
\hline \multirow[t]{2}{*}{ Variable } & \multirow[t]{2}{*}{ Cutoff } & \multicolumn{2}{|l|}{ Univariate } & \multicolumn{2}{|l|}{ Multivariate } \\
\hline & & Odds ratio $(95 \% \mathrm{Cl})$ & $P$ value & Odds ratio $(95 \% \mathrm{Cl})$ & $P$ value \\
\hline Age, years & $\geq 68$ versus $<68$ & $0.89(0.52-1.54)$ & 0.78 & & \\
\hline $\mathrm{BMI}, \mathrm{kg} / \mathrm{m}^{2}$ & $\geq 25$ versus $<25$ & $2.02(1.17-3.48)$ & $0.01 *$ & $1.80(1.03-3.12)$ & $0.03^{*}$ \\
\hline $\mathrm{iPSA}, \mathrm{ng} / \mathrm{mL}$ & $\geq 7.6$ versus $<7.6$ & $1.43(0.82-2.48)$ & 0.22 & & \\
\hline Diabetes & With versus without & $0.19(0.04-0.80)$ & $0.01^{*}$ & & \\
\hline COPD & With versus without & $0.45(0.10-1.91)$ & 0.42 & & \\
\hline $\mathrm{HD}$ & With versus without & $1.55(0.53-4.51)$ & 0.34 & & \\
\hline Abdominal surgery & With versus without & $1.04(0.56-1.92)$ & 0.87 & & \\
\hline \multirow[t]{3}{*}{ Surgeon volume, cases } & $\geq 20$ versus $<20$ & $0.95(0.55-1.66)$ & 0.88 & & \\
\hline & $\geq 40$ versus $<40$ & $0.84(0.48-1.49)$ & 0.67 & & \\
\hline & $\geq 100$ versus $<100$ & $0.66(0.27-1.57)$ & 0.44 & & \\
\hline Nerve sparing & With versus without & $0.92(0.52-1.64)$ & 0.88 & & \\
\hline Duration of console, min & $\geq 184$ versus $<184$ & $2.00(1.13-3.54)$ & $0.01^{*}$ & $1.84(1.03-3.28)$ & $0.03^{*}$ \\
\hline Prostate weight, g & $\geq 40$ versus $<40$ & $1.80(0.99-3.27)$ & 0.05 & $1.69(0.93-3.09)$ & 0.08 \\
\hline Blood, mL & $\geq 230$ versus $<230$ & $1.26(0.73-2.17)$ & 0.41 & & \\
\hline $\mathrm{pGS} \geq 8$ & $\geq$ versus $<$ & $0.86(0.46-1.58)$ & 0.76 & & \\
\hline pT3 & $\geq$ versus $<$ & $0.98(0.54-1.77)$ & 1.00 & & \\
\hline PSM & With versus without & $0.80(0.39-1.62)$ & 0.61 & & \\
\hline
\end{tabular}

BMI, body mass index; COPD, chronic obstructive pulmonary disease; IHD, ischemic heart disease; PSA, prostate specific antigen; pGS, pathological Gleason score; PSM, positive surgical margin

Statistical significance is shown as * for $P<0.05$

Table 3 Univariate and multivariate analysis to predict major anastomotic urinary leakage (AUL)

\begin{tabular}{|c|c|c|c|c|c|}
\hline \multirow[t]{2}{*}{ Variable } & \multirow[t]{2}{*}{ Cutoff } & \multicolumn{2}{|l|}{ Univariate } & \multicolumn{2}{|l|}{ Multivariate } \\
\hline & & Odds ratio $(95 \% \mathrm{Cl})$ & $P$ value & Odds ratio $(95 \% \mathrm{Cl})$ & $P$ value \\
\hline Age, years & $\geq 68$ versus $<68$ & $0.64(0.27-1.50)$ & 0.38 & & \\
\hline $\mathrm{BMI}, \mathrm{kg} / \mathrm{m}^{2}$ & $\geq 25$ versus $<25$ & $4.30(1.73-10.66)$ & $<0.01^{* *}$ & $3.62(1.44-9.09)$ & $0.01^{*}$ \\
\hline iPSA, ng/mL & $\geq 7.6$ versus $<7.6$ & $1.42(0.60-3.36)$ & 0.51 & & \\
\hline Diabetes & With versus without & $0.26(0.03-1.95)$ & 0.23 & & \\
\hline COPD & With versus without & 0 & 0.39 & & \\
\hline $\mathrm{IHD}$ & With versus without & $1.99(0.45-8.83)$ & 0.29 & & \\
\hline Abdominal surgery & With versus without & $0.44(0.12-1.51)$ & 0.22 & & \\
\hline \multirow[t]{3}{*}{ Surgeon volume, cases } & $\geq 20$ versus $<20$ & $0.96(0.40-2.28)$ & 1.00 & & \\
\hline & $\geq 40$ versus $<40$ & $0.44(0.16-1.22)$ & 0.12 & & \\
\hline & $\geq 100$ versus $<100$ & $0.88(0.25-3.03)$ & 1.00 & & \\
\hline Nerve sparing & With versus without & $1.03(0.43-2.50)$ & 1.00 & & \\
\hline Duration of console, min & $\geq 184$ versus $<184$ & $2.69(1.04-6.94)$ & $0.04^{*}$ & $2.23(0.85-5.85)$ & 0.09 \\
\hline Prostate weight, g & $\geq 40$ versus $<40$ & $3.20(1.07-9.56)$ & $0.02^{*}$ & $2.47(0.95-6.43)$ & 0.06 \\
\hline Blood, mL & $\geq 230$ versus $<230$ & $1.46(0.61-3.46)$ & 0.39 & & \\
\hline $\mathrm{pGS} \geq 8$ & $\geq$ versus $<$ & $0.69(0.25-1.90)$ & 0.63 & & \\
\hline pT3 & $\geq$ versus $<$ & $1.58(0.67-3.76)$ & 0.34 & & \\
\hline PSM & With versus without & $0.82(0.27-2.47)$ & 1.00 & & \\
\hline
\end{tabular}

BMI, body mass index; COPD, chronic obstructive pulmonary disease; IHD, ischemic heart disease; PSA, prostate specific antigen; pGS, pathological Gleason score; PSM, positive surgical margin

Statistical significance is shown as * for $P<0.05$ and ${ }^{*}$ for $P<0.01$ 


\section{Discussion}

AUL has been reported to occur in $0.3-15.4 \%$ of patients after RARP [12]. In our study, the incidence of AUL detected by cytogram was $6.1 \%$, which was compatible with other reports. However, the incidence of AUL varies greatly with parameters such as postoperative date, as demonstrated in a study that showed decreasing rates of AUL incidence with a lapse of time after RRP [13]. Although the timing of postoperative cystograms from past studies range from 3-18 days and requires standardization [14-16], we set the timing of cystogram at POD $6-8$, which appears to be consistent with many of the previous reports $[3,5,8,9,17]$.

We examined post-operative continence rates and found that time to recovery of continence was negatively affected by the presence of major AUL on cystogram. This result was in line with past reports that also found an association between AUL and post-operative continence $[5,18]$. This leads us to believe that major AUL is of clinical importance and that examination of factors contributing to its incidence would be beneficial in predicting postoperative outcomes.

The predictive factors of AUL have been examined in multiple previous studies. Some factors presented were obesity/BMI, ischemic heart disease, urinary tract infection, excessive blood loss, surgeon experience, eversion of the bladder mucosa, prostate size, previous prostatic surgery, or details regarding surgical technique (bladder neck eversion, posterior reconstruction, etc.) [4, 9, 1922]. In the univariate analysis of the present study, longer console time, larger prostate weight, and higher BMI was associated with AUL. Furthermore, in the multivariate analysis, longer console time and higher BMI were significant factors of overall AUL and higher BMI was a significant factor of major AUL.

Obesity may create difficulties in accessing the vesicourethral anastomosis site or to decrease visibility. Some reports state that this only applies to RRP, while others assert that obesity also affects outcomes of RARP negatively [21, 23]. Excessive bleeding may cause natural ischemia in the bladder or urethral tissue. They also lead to impairment of visibility, making precise suture placement difficult. Unavoidable suture for maintaining hemostasis may cause further ischemia. Past studies have also reported that the postoperative bleeding was a predictor of AUL and that this was likely the result of paraanastomotic hematoma delaying the healing of UVA [17, 24]. Tillier et al. asserted that men with larger prostate size and preoperative voiding problems were predictive of major leakage in RARP due to bladder neck reconstruction and the alignment of the bladder and urethra [9]. It is obvious that the larger the prostate, the longer the distance between the bladder neck and urethra after excision of the prostate, resulting in a more challenging UVA. Console time was not mentioned in any previous study, yet it remained a predictive factor in multivariate analysis for overall AUL in our study. We surmised that console time may have been a manifestation of the level of difficulty in conducting the surgery, and in some cases the difficulty of UVA.

The above observations seem to show that difficulty in conducting the anastomosis may be a predictor of AUL. Although based on one surgeon's subjective assessment, Gnanapragasam et al. reported that a 'difficult anastomosis' was indeed an independent predictor of AUL [20]. There is also evidence that the quality of anastomosis was associated with surgeon experience [3]. We hypothesized that surgeon experience may be related to AUL and included surgeon experience as a factor, but we did not identify any association with the surgeon volume and AUL in our cohort. This may partly be due to the unique mentoring system we implemented, in which RARP was divided into sections, each with a designated time limit and blood loss criteria, and an experienced surgeon replaced an inexperienced surgeon for the remainder of the section upon exceeding the designated time or blood loss [10, 25].

A postoperative cystogram is considered a valuable diagnostic tool to detect urinary extravasation after RARP. However, it is not performed routinely at many centers around the world. Guru et al. reported that removal of catheter on postoperative days 8-10 without performing cystogram may not lead to complications in patients with RARP [26]. Although this prospective study was low-powered and consisted of only eighty patients recruited at a single institution, the fact remains that the fairly small percentage of men who develop complications relating to AUL may not be enough to justify the cost and manpower incurred by a routine cytogram for all patients with RARP. One prospective study consisting of 230 patients at a single institution indicated that selective cystogram is preferable in cases with bladder neck resection or a history of transurethral resection of the prostate [27]. Tillier et al. similarly suggested that selective cystogram in cases with larger prostate and with preoperative voiding problems may prevent early urinary retention and alleviate voiding complaints [9]. Based on these reports, a selective cystogram may be more beneficial than a routine cystogram. Prospective randomized studies under further standardization of cystogram protocols are required to better support this idea.

There are several limitations to discuss. First, this study was not a prospective randomized study, and further investigation is needed to confirm our assertion. Second, although our study analyzed the findings of a postoperative cystogram according to the criteria as defined by 
Williams et al., the degree of AUL would be influenced by the amount and speed of contrast instilled into the bladder, and hence cannot be said to completely adhere to the original report [8]. Third, we may underestimate the relationship between the surgical skill and the incidence of AUL since we only examined the total console time and not the actual time to complete UVA.

\section{Conclusion}

In conclusion, we objectively examined the results of a routine cystogram after RARP and found that major AUL was associated with a longer time to recovery of continence. BMI was identified as the predictor of overall and major AUL and may be taken into consideration when performing selective cystograms after RARP.

\section{Abbreviations}

AUL: Anastomotic urinary leakage; BMI: Body mass index; GS: Gleason score; UVA: Urethrovesical anastomosis; LRP: Laparoscopic radical prostatectomy; PSA: Prostate specific antigen; PSM: Positive surgical margin; RARP: Robotassisted radical prostatectomy; RRP: Retropubic radical prostatectomy.

\section{Acknowledgements}

The authors would like to thank K. Kawabe (former Professor of the Department of Urology, The University of Tokyo) and T. Kitamura (Honorary Professor of the Department of Urology, The University of Tokyo), for referring many of the patients included in the study.

\section{Authors' contributions}

SK and YT contributed equally to this work. YY contributed to the study conception and designed the study. SK, YT, and $Y Y$ wrote the manuscript. $Y H$, TT, NK, YS, YA, TK, DY, TF, and YY collected the data at the University of Tokyo Hospital. SK, SN, YE constructed the database in the Mitsui Memorial Hospital. YY and SK constructed the database in Chiba Tokushukai Hospital. YY and SK contributed to integrating the database and analyzing the data. HK assisted in all process of this study. All authors read and approved the final manuscript.

\section{Availability of data and materials}

The datasets generated during the current study are not publicly available due to on-going clinical studies based on the database but are available from the corresponding author on reasonable request.

\section{Declarations}

Ethics approval and consent to participate

The study was carried out according to The Declaration of Helsinki and approved by the ethical committee of The University of Tokyo Hospital (ID: 2020039NI), the ethical committee of Mitsui Memorial hospital (ID: 2020C30), and the committee of Chiba Tokushukai Hospital (ID: 184). Written informed consent was obtained from each patient.

\section{Consent for publication}

Not applicable.

\section{Competing interests}

The authors declare that they have no competing interests.

\section{Author details}

${ }^{1}$ Department of Urology, Chiba Tokushukai Hospital, Chiba, Japan. ${ }^{2}$ Department of Urology, Graduate School of Medicine, The University of Tokyo, 7-3-1 Hongo, Bunkyo-Ku, Tokyo 113-8655, Japan. ${ }^{3}$ Division of Innovative Cancer Therapy, Advanced Research Center, The Institute of Medical Science, The University of Tokyo, Minato-Ku, Tokyo, Japan. ${ }^{4}$ Department of Urology, Jichi
Medical University, Tochigi, Japan. ${ }^{5}$ Department of Urology, Mitsui Memorial Hospital, Tokyo, Japan.

Received: 8 February 2021 Accepted: 20 April 2021

Published online: 03 May 2021

\section{References}

1. Du Y, Long Q, Guan B, Mu L, Tian J, Jiang Y, Bai X, Wu D. Robot-assisted radical prostatectomy is more beneficial for prostate cancer patients: a system review and meta-analysis. Med Sci Monit. 2018;24:272-87. https:// doi.org/10.12659/msm.907092.

2. Basiri A, de la Rosette JJ, Tabatabaei S, Woo HH, Laguna MP, Shemshaki H. Comparison of retropubic, laparoscopic and robotic radical prostatectomy: who is the winner? World J Urol. 2018;36:609-21. https://doi.org/ 10.1007/s00345-018-2174-1.

3. Moro FD, Beltrami P, Zattoni F. Can anastomotic urinary leakage in robotic prostatectomy be considered as a marker of surgical skill? Cent Eur J Urol. 2017;71:21-5. https://doi.org/10.5173/ceju.2018.1587.

4. Webb DR, Sethi K, Gee K. An analysis of the causes of bladder neck contracture after open and robot-assisted laparoscopic radical prostatectomy. BJU Int. 2009;103:957-63. https://doi.org/10.1111/j.1464-410X. 2008.08278.x

5. Patil N, Krane L, Javed K, Williams T, Bhandari M, Menon M. Evaluating and grading cystographic leakage: correlation with clinical outcomes in patients undergoing robotic prostatectomy. BJU Int. 2009;103:1108-10. https://doi.org/10.1111/j.1464-410X.2008.08168.x.

6. Jacobsen A, Berg KD, Iversen P, Brasso K, Røder MA. Anastomotic complications after robot-assisted laparoscopic and open radical prostatectomy. Scand J Urol. 2016;50:274-9. https://doi.org/10.3109/21681805.2016. 1145735.

7. Rebuck DA, Haywood S, McDermott K, Perry KT, Nadler RB. What is the long-term relevance of clinically detected postoperative anastomotic urine leakage after robotic-assisted laparoscopic prostatectomy? BJU Int. 2011;108:733-8. https://doi.org/10.1111/j.1464-410X.2010.09939.x.

8. Williams TR, Longoria OJ, Asselmeier S, Menon M. Incidence and imaging appearance of urethrovesical anastomotic urinary leaks following da Vinci robotic prostatectomy. Abdom Imaging. 2008;33:367-70. https://doi.org/ 10.1007/s00261-007-9247-8

9. Tillier C, Van Muilekom HAM, Bloos-van der Hulst J, Grivas N, Van der Poel HG. Vesico-urethral anastomosis (VUA) evaluation of short- and long-term outcome after robot-assisted laparoscopic radical prostatectomy (RARP): selective cystogram to improve outcome. J Robot Surg. 2017;11:441-6.

10. Fujimura T, Menon M, Fukuhara H, Kume H, Suzuki M, Yamada Y, Niimi A, Nakagawa T, Igawa Y, Homma Y. Validation of an educational program balancing surgeon training and surgical quality control during robotassisted radical prostatectomy. Int J Urol. 2016;23:160-6. https://doi.org/ 10.1111/iju.12993.

11. Kakutani S, Asamoto M, Araki F, Chen YN, Shinokawa M, Okagami Y, Ohata T, Taguchi S, Yamada Y, Takeshima Y, Kume H, Yamada Y, Aihara M, Ito N, Fukuhara $\mathrm{H}$. Prospective evaluation of visual function in patients with ocular diseases after robot-assisted laparoscopic prostatectomy. Int J Urol. 2020;27:307-12. https://doi.org/10.1111/iju.14183.

12. Tyritzis SI, Katafigiotis I, Constantinides CA. All you need to know about urethrovesical anastomotic urinary leakage following radical prostatectomy. J Urol. 2012;188:369-76. https://doi.org/10.1016/j.juro.2012.03.126.

13. Dalton DP, Schaeffer AJ, Garnett JE, Grayhack JT. Radiographic assessment of the vesicourethral anastomosis directing early decatheterization following nerve-sparing radical retropubic prostatectomy. J Urol. 1989;141:79-81. https://doi.org/10.1016/s0022-5347(17)40595-7.

14. Schatzl G, Madersbacher S, Hofbauer J, Pycha A, Reiter WJ, Svolba G, Marberger M. The impact of urinary extravasation after radical retropubic prostatectomy on urinary incontinence and anastomotic strictures. Eur Urol. 1999;36:187-90. https://doi.org/10.1159/000067995.

15. Menon M, Hemal AK, Tewari A, Shrivastava A, Bhandari A. The technique of apical dissection of the prostate and urethrovesical anastomosis in robotic radical prostatectomy. BJU Int. 2004;93:715-9. https://doi.org/10. 1111/j.1464-410X.2003.04748.X.

16. Gratzke C, Dovey Z, Novara G, Geurts N, De Groote R, Schatteman P, de Naeyer G, Gandaglia G, Mottrie A. Early catheter removal after 
robot-assisted radical prostatectomy: surgical technique and outcomes for the aalst technique (ECaRemA Study). Eur Urol. 2016;69:917-23. https://doi.org/10.1016/j.eururo.2015.09.052.

17. Fenig DM, Slova D, Lepor H. Postoperative blood loss predicts the development of urinary extravasation on cystogram following radical retropubic prostatectomy. J Urol. 2006;175:146-50. https://doi.org/10. 1016/S0022-5347(05)00051-0.

18. Ha YS, Bak DJ, Chung JW, Lee JN, Kwon SY, Choi SH, Kwon TG. Kim THPostoperative cystographic findings as an independent predictor of urinary incontinence three months after radical prostatectomy. Minerva Urol Nephrol. 2017;69:278-84.

19. Ramsden AR, Chodak GW. Can leakage at the vesico-urethral anastomosis be predicted after radical retropubic prostatectomy? BJU Int. 2004;93:503-6. https://doi.org/10.1111/j.1464-410x.2003.04668.x.

20. Gnanapragasam VJ, Baker P, Naisby GP, Chadwick D. Identification and validation of risk factors for vesicourethral leaks following radical retropubic prostatectomy. Int J Urol. 2005;12:948-52. https://doi.org/10.1111/j. 1442-2042.2005.01166.x.

21. Sandhu JS, Gotto GT, Herran LA, Scardino PT, Eastham JA, Rabbani F. Age, obesity, medical comorbidities and surgical technique are predictive of symptomatic anastomotic strictures after contemporary radical prostatectomy. J Urol. 2011;185:2148-52. https://doi.org/10.1016/j.juro.2011.02. 003.

22. Coelho RF, Chauhan S, Orvieto MA, Sivaraman A, Palmer KJ, Coughlin $G$, Patel VR. Influence of modified posterior reconstruction of the rhabdosphincter on early recovery of continence and anastomotic leakage rates after robot-assisted radical prostatectomy. Eur Urol. 2011;59:72-80. https://doi.org/10.1016/j.eururo.2010.08.025.

23. Herman MP, Raman JD, Dong S, Samadi D, Scherr DS. Increasing body mass index negatively impacts outcomes following robotic radical prostatectomy. JSLS. 2007;11(4):438-42.

24. O'Malley RL, Telegrafi S, Laze J, Lepor H. Para-anastomotic haematoma volume predicts the presence of anastomotic extravasation after radical retropubic prostatectomy. BJU Int. 2010;105:34-6. https://doi.org/10. 1111/j.1464-410X.2009.08709.x.

25. Yamada Y, Teshima T, Fujimura T, Sato Y, Nakamura M, Niimi A, Kimura N, Kakutani S, Kawai T, Yamada D, Suzuki M, Kume H. Comparison of perioperative outcomes in elderly (age $\geqq 75$ years) versus younger men undergoing robot-assisted radical prostatectomy. PLoS ONE. 2020;15:e0234113. https://doi.org/10.1371/journal.pone.0234113.

26. Guru KA, Seereiter PJ, Sfakianos JP, Hutson AD, Mohler JL. Is a cystogram necessary after robot-assisted radical prostatectomy? Urol Oncol. 2007;25:465-7. https://doi.org/10.1016/j.urolonc.2007.01.014.

27. Yadav R, Bansal S, Gupta NP. Selective indication for check cystogram before catheter removal following robot assisted radical prostatectomy. Indian J Urol. 2016;32:120-3. https://doi.org/10.4103/0970-1591.174776.

\section{Publisher's Note}

Springer Nature remains neutral with regard to jurisdictional claims in published maps and institutional affiliations.
Ready to submit your research? Choose BMC and benefit from:

- fast, convenient online submission

- thorough peer review by experienced researchers in your field

- rapid publication on acceptance

- support for research data, including large and complex data types

- gold Open Access which fosters wider collaboration and increased citations

- maximum visibility for your research: over $100 \mathrm{M}$ website views per year

At BMC, research is always in progress.

Learn more biomedcentral.com/submissions 